\title{
Current state and main directions of innovative development of placer gold mining in Far East Federal District
}

\author{
Viktor Litvinsev ${ }^{1 *}$ and Petr Sas ${ }^{1}$ \\ ${ }^{1}$ Mining Institute of Far Easten Branch of Russian Academy of Sciences, Khabarovsk, Russia
}

\begin{abstract}
Based on the assessment of the resource base of Far East region of Russia, the important role of the mining industry for most regions of Far East Federal District was noted. A decrease in the resource potential of geogenous placers has been established, therefore anthropogenic deposits of placer deposits become an important reserve of placer gold mining. Natural and technological factors that need to be taken into account when selecting and applying those technologies and mining equipment that can reduce their influence are as follows: permafrost rocks, high clayey sand deposits, large content of fine and fine fractions of gold, the presence of high content of heavy fractions of other valuable passing components, etc. A number of developed innovative technologies for development of alluvial deposits, as well as new technological equipment for use on dredges and drags, have been noted. The parameters of the technological processes of the jigging machine on the Alaska-35 washing device (USA) have been analyzed, the matrix of interacting factors (such as the shape of the particles of a mineral, particle size, particle density, height of the bed of the jigging machine, frequency of piston swings, stroke of piston, etc.), the purpose of the study is to obtain graph-analytical dependencies for calculating their rational parameters that ensure effective extraction of metals. Keywords: Alluvial deposits, innovative technologies for placer mining, interacting factors, jigging machines.
\end{abstract}

\section{Introduction}

Russian Far East has rich and diverse natural resources. In a number of its regions, the mining industry is practically the only sector of the national economy.

The main types of minerals, which are mined in Far East, are gold, platinum, silver, diamonds, tin, lead and zinc, tungsten, coal, boron, fluorite, oil and gas.

Far East takes the second in terms of explored balance reserves of gold, and the first place in Russia for mining from subsoil. In forecasted resources, the leading position currently belongs to core gold $(81.3 \%)$, with a substantially subordinate value of placer $(13.4 \%)$ and gold in complex deposits.

Corresponding author: litvinzev@igd.khv.ru 
3,305 gold deposits were registered on the territory of the federal district, of which 180 indigenous (including 14 complex) and 3,153 alluvial deposits. The largest number of alluvial deposits is located in Magadan Region (39\%) and Republic of Sakha $(24.3 \%)$, Chukotka Autonomous District - 12.1\%, Khabarovsk Region - 10.3\% and Amur Region $9 \%$ of the gold deposits [1].

The mining of alluvial gold is a traditional branch of the economy of Russian Far East practically since the development of this territory. For more than a century of history, more than 1,500 tons of precious metal has been extracted from the placers of Far East. The share of gold mining from placers in the total volume of gold mining in Russia was $70-75 \%$ at the end of the 20th century, however, at the beginning of the third millennium a definite decline was observed, due both to the development of easily accessible and rich placers, and to a decrease in the volumes of geological exploration. During this period, there was also a significant decrease in the number of prospecting artels, which negatively affected a number of regions of Far East Federal District in the economic and social aspects.

The main resource of placer gold mining in Russia is man-made complexes of geogenous alluvial deposits. Their reserves of rock mass are several billion cubic meters, and the estimated resources in Russia are estimated at over 5,000 tons.

Table 1 presents Far East regions that have a certain number of locations of placer gold, as well as the dynamics of their exploration and development.

The data in Table 1 indicate a very low level of exploration (with the exception of Magadan Region), when the number of recovered placers exceeds the number of explored and registered.

Table 1 - Number of placer gold deposits in the regions of Far East Federal District and the dynamics of their exploration and development

\begin{tabular}{|l|c|c|}
\hline \multirow{2}{*}{\multicolumn{1}{|c|}{ Region }} & \multicolumn{2}{c|}{ Number of gold placers in Far East Federal Dis- } \\
\cline { 2 - 3 } & $2016-2017$ & 2012 \\
\hline Magadan Region & 1.242 & 1.172 \\
\hline Republic of Sakha (Yakutia) & 760 & 771 \\
\hline Chukotka Autonomous District & 381 & 380 \\
\hline Khabarovsk Region & 323 & 342 \\
\hline Amur Region & 278 & 643 \\
\hline Primorsk Region & 71 & 82 \\
\hline Kamchatka Region & 49 & 51 \\
\hline Jewish Autonomous Republic & 28 & 29 \\
\hline Sakhalin Region & 21 & 26 \\
\hline Total & 3.153 & 3.496 \\
\hline
\end{tabular}

\section{Current state and analysis of problems in the development of precious metals placer deposits}

Given the scarcity of easily accessible geogenous placer deposits with a rich content of large recoverable gold and gold orientation of anthropogenic sets of placers, it is necessary to assess the negative natural factors that should be considered when selecting and applying those technologies and mining equipment that can reduce their impact .

First, the permafrost nature of the rocks of deposits. In the southern part of Russian Far East, placers are almost unaffected by permafrost, although in certain periods some territories fall into year-round cryolithozones, which could not but affect the nature of lithogenesis [2].

Second, the presence of vast fields of argillite, poorly metamorphosed rocks, ore-forming fea- 
tures of the indigenous sources - all this created conditions for the formation of placers containing a significant amount of thin and fine gold and high clay content of host rocks, which is even more so in their anthropogenic objects.

Third, in conditions of a small depth of freezing of rocks (up to 2 meters), the clays of the underlying horizons, both natural and anthropogenic placers, are not affected by frost destruction, retaining their plastic state, which leads to very significant metal losses, not only thin and fine, but also gravitationally enriched, both contained inside the clays and adsorbed from already washed sand by the surfaces of clay "pellets" and carried away to the dump. Only in the Khabarovsk region of such deposits there are up to $30 \%$ and only $15 \%$ are light-washable.

Fourth, placer deposits with a high content of minerals in the heavy fraction, which in some cases reach $16.4 \mathrm{~kg}$ per $1 \mathrm{~m} 3$, belong to rebellious placers.

To achieve the optimum development of placer deposits with the use of widely-used washing equipment, it is necessary to identify the most important factors and find the regularities of their comprehensive influence on the choice of rational parameters of technological processes and constructive specifications of the enrichment equipment (Table 2).

Table 2 - Factors influencing the effective development of placer deposits

\begin{tabular}{|c|c|c|}
\hline No. & Factors & Factor description \\
\hline 1 & Mining and geological & $\begin{array}{l}\text { - Granulometric composition of the sands of placer de- } \\
\text { posits; } \\
\text { - Sieve characteristic of gold; } \\
\text { - Morphology of metal; } \\
\text { - Presence of associated minerals (hematite, } \\
\text { wolframite, magnetite, etc.); } \\
\text { - Presence of clay fractions; } \\
\text { - Presence of permafrost. }\end{array}$ \\
\hline 2 & Technological & $\begin{array}{l}\text { - Possibility of modernization of concentrating equip- } \\
\text { ment parts; } \\
\text { - Regulation of parameters of technological processes } \\
\text { of concentrating equipment. }\end{array}$ \\
\hline
\end{tabular}

At present, only some specific dependencies of the influence of the factors listed in Table 3 on the metal recovery efficiency have been obtained.

At present, in most cases, an open method for the development of alluvial deposits prevails with the use of such domestic washers as PGSh (70\%), PKBSh, PBSh (scrubbers 20\%), GGM-5, foreign ones - Alaska-35, etc. The underground method is characteristic mainly for the north of Far East Federal District, it is Chukotka (Riveyem), Yakutia (Kular). Underwater method (dredging technology) is concentrated in Amur region (Solovyovsk mine) and Magadan region (Susumanzoloto). The combined method is mainly open-offshore (Magadan Region) and open-underground (Chukotka) [3, 4].

Machine builders began to focus on increasing the productivity of devices (GGM-3, PPM-5 devices of Magadan Mechanical Plant with a capacity of 100 to $250 \mathrm{~m} 3 / \mathrm{h}$ ) and complicating their design features in order to increase the extraction of gold, including fine and thin; they started using lapping equipment in the form of centrifugal concentrators, both Russian and foreign. More complete extraction of gold has already become for subsoil users a need for cost-effective development of deposits. However, a relatively high cost of additional equipment, time lost during the rearrangement of complicated devices does not always allow them to be brought into production, and therefore many enterprises have preserved the traditional approaches to gold mining and technological equipment back from the 1960s, which inevitably leads to a high level of metal loss [5]. 


\section{Results}

In Institute of Mining of Far East Division of Russian Academy of Sciences, for several years, studies were carried out to create samples of mining equipment that enhance the extraction of gold from placer deposits.

The most effective studies were related to the processing of the efel tails of a dredge on a conical hydro-groove (Solovyovsk mine). A mathematical model was developed for calculating the parameters of a two-phase swirling hydraulic flow of a conical hydro-grate, which is the technological basis for increasing the extraction efficiency of fine and thin gold. The developed sectional design of the hydro-grate is protected by a RF patent.

The prospect of using the dredging technology for the development of anthropogenic placers underwater has been determined, and equipment has been developed to increase the extraction of large fractions of the valuable component from the rock floor of the deposit.

It is possible to give a number of examples of the development of technological equipment in MI FEB RAS, however, the effectiveness of its implementation is weak, since subsoil users are not interested (or do not have the financial and technological resources) to make it in metal, they need, at best, ready samples of mining equipment.

Promising innovative technologies in the laboratory are actively developing those associated with the involvement in operation of anthropogenic sets of placer deposits. This technology is the formation of a productive reservoir of the anthropogenic complex by the impact of non-pressure water flows and the technology of simultaneous development of closely related anthropogenic and geogenic (low-volume or with a small gold content) placer deposits, with the complex extraction of valuable components at a stationary washing device.

In the current period, studies were carried out to assess the complex effect of natural and technological factors on the efficiency of jigging machines. They are an effective technological equipment for extracting various, including small, fractions of gold, however their operation requires high-tech maintenance.

Jigging technology was widely used in 40-60 years of the last century, mainly in the enrichment of coal and placer deposits of tin. In placer gold mining, this technology was occasionally used for finishing operations in the placer gold concentrating site. In the late 1970s, a sharp decline in the development of this field began, one of the main reasons for this being a decrease in the volume of tin mining.

Currently, this technology begins to revive in placer gold mining, but it turned out that, in many ways, the skills and knowledge on the operation of jigging machines were lost. Without knowledge of the operating modes, the conditions for formation of the artificial bed of jigging machine, the rational amount of back water, the magnitude of the piston stroke and other parameters, jigging machines cannot work effectively. Many domestic and foreign manufacturers of jigging machines do not give specific recommendations on their operating modes for particular mineral raw material, because in the enrichment of coal, placer gold and other minerals, in each case there must be special operating modes of the jigging machine.

A great contribution in the field of research of jigging technology was made in the 20th century by Soviet and foreign scientists: Kizevalter, Fomenko, Kuznetsov, Rafales-Lamark, Verkhovsky, Margolin, Fomin, Bochkovsky, Kachan, Samylin, Polkinin, Bert, Taggart, Mayer, Yoshida, Tsimmerman.

As a foreign analogue of jigging machines, it is known to use a jigging machine IHC (Holland), when operating it, about $90 \%$ of the sands are released in tailings, but small fractions of gold were also extracted $[6,7]$. 
Questions of the theory and practice of jigging are most fully developed for the separation of large and medium fractions of minerals. The rational parameters of deposition of fine and thin fractions have not been substantiated, either practically or theoretically. Therefore, the purpose of the studies performed was to reveal the patterns of influence of various mineralogical and technological factors on the efficiency of gold recovery using jigging machines of Alaska-35 (US) industrial equipment. Such factors include: the ratio of solidliquid of super-plate water, the amount of sub-surface water, the frequency and stroke of the piston, the thickness of the bed of the jigging machine, the density of the bed material. The granulometric composition of the mineral mass of sands also has a significant effect.

At the first stage of the study, only a small number of factors that have the greatest impact on the jigging process were examined: this is the mineral density, the amount of subsurface water, the thickness of the jig-bed, the frequency and the stroke of the working piston. The following results were obtained in the study of the parameters of the jigging machine operation using Alaska-35 washing device:

a) Influence of volumes of processed sands on the efficiency of jigging

It has been found that with increasing load, the recovery of the useful component and the yield of the concentrate decreases, since the bed density in the jigging machine increases due to the saturation of its pores with grains of heavy minerals.

b) Influence of volumes of top and back water

With a high density of minerals on the bed of the jigging machine, it is necessary to increase the ratio of solid to liquid $(\mathrm{S}: \mathrm{L})$ of the pulp from 1:1 to 1:4. At a higher $\mathrm{S}: \mathrm{L}$, a reduction in the recovery of mineral is observed. The supply of back water significantly affects the amount of metal loss. With the help of back water, it is possible to increase the ascending velocity and reduce the down-flow velocity, and to slow the movement of particles from the upper light layers of the bed to the drain threshold of the machine. Thus, the back water promotes an increase in looseness of the bed in an upward flow and a decrease in losses of small classes of gold in a downward flow.

c) Effect of bed height on the jigging process

Bedding is the most important technological factor of the jigging process. Only thanks to the selection of bed material (by density, by particle size), it is possible to achieve selective separation of the mixture and, ultimately, to achieve a high recovery of the useful component.

The results of experimental studies (ten experiments) made it possible to obtain an equation for the dependence of the yield of the undersize on the height of the bed at a constant value of the piston oscillation. The sought equation of quadratic regression has the form:

$$
\mathrm{Y}=0.133 \mathrm{~B}^{2}-0.74 \mathrm{~B}+11.6
$$

where $\mathrm{Y}$ - yield of the undersize, \%;

$\mathrm{B}$ - bed height, mm. continued.

Only a small part of the interacting factors was analyzed, so in 2017 the research was

In 2017, experimental work was carried out on a laboratory jigging machine produced by TsNIGRI (Central Geological Research Institute for Nonferrous and Precious Metals). The jigging machine consists of 2 chambers, each $100 \mathrm{~cm}^{2}$ area. The stroke length is adjustable from $1.5 \mathrm{~mm}$ to $12 \mathrm{~mm}$, with 8 fixed positions, has 3 vibration frequencies -180 $\mathrm{rpm}, 200 \mathrm{rpm}$ and $240 \mathrm{rpm}$. 


\section{Description of experimental works}

A total sample weighing $18 \mathrm{~kg}$ was divided into three parts, then averaged. The average mass of the sample was $2,200 \mathrm{~g}$, the density was $1.7 \mathrm{~g} / \mathrm{cm}^{3}$, the amount of top water was 1 $1 / \mathrm{min}$, the amount of back water in chamber 1 was $21 / \mathrm{min}$, in chamber $2-11 / \mathrm{min}$. The time of processing the sample on the jigging machine averaged 25-30 minutes.

Under the influence of the upward flow of water, the mineral mixture is loosened and light-mineral particles with velocity of fall is less than the upward flow rate rise into the upper layers of the material. Particles of the heavy mineral are in this case in a suspended state, and then in the downward flow they occupy the bottom layer.

Tables 3 and 4 show the extraction of gold on the jigging machine when the stroke of the piston is changed at a frequency of $240 \mathrm{rpm}$ and $200 \mathrm{rpm}$, respectively.

From these tables it is possible to draw a preliminary conclusion that as the piston stroke frequency decreases, the metal losses decrease, the concentration increases in chamber 1 , in the oversize and undersize. The stroke of piston in the actual experiments did not have a significant effect, but it is required to conduct repeated studies. It is necessary to continue laboratory work in order to identify the main factors affecting the jigging process.

\section{Conclusions}

A characteristic of the resource base of Russian Far East is given, an important role of the mining industry for the majority of the regions of Far East Federal District is noted. It is established that an important reserve of placer gold mining is anthropogenic sets of placer deposits.

An assessment of negative natural factors that should be taken into account when selecting and applying those technologies and mining equipment that can reduce their influence has been made - namely, the permafrost of rocks, high clayey sand of placers and a large content of fine and thin fractions of gold, high content of heavy fractions of other valuable passing components, etc.

The availability of developed innovative technologies for the use of placer deposits, as well as new technological equipment for use in dredges and drag was reflected.

Table 3. Extraction of gold on the jigging machine with a change in the stroke of piston at a frequency of $240 \mathrm{rpm}$

\begin{tabular}{|c|c|c|c|c|c|c|c|c|}
\hline \multirow{2}{*}{$\begin{array}{c}\text { Piston } \\
\text { stroke, } \\
\text { mm }\end{array}$} & $\begin{array}{c}\text { No. of } \\
\text { sample }\end{array}$ & $\begin{array}{c}\text { Mass of } \\
\text { sample, } \\
\mathrm{g}\end{array}$ & $\begin{array}{c}\text { Top } \\
\text { chamber } \\
1\end{array}$ & $\begin{array}{c}\text { Top } \\
\text { chamber } \\
2\end{array}$ & $\begin{array}{c}\text { Underflow } \\
\text { chamber 1 }\end{array}$ & $\begin{array}{c}\text { Underflow } \\
\text { chamber 2 }\end{array}$ & $\begin{array}{c}\text { Jig } \\
\text { tailings }\end{array}$ & $\begin{array}{c}\text { Total } \\
\text { Au, } \\
\text { mg }\end{array}$ \\
\hline 1.5 & $\mathrm{P}-1$ & $2,371.5$ & 55.16 & 19.66 & 18.63 & 4.02 & 2.53 & 20,40 \\
\hline 3 & $\mathrm{P}-2$ & 2,210 & 5.82 & 1.28 & 82.47 & 4.07 & 6.36 & 12,89 \\
\hline 4 & $\mathrm{P}-3$ & 2,200 & 66.62 & 6.30 & 26.56 & 0.07 & 0.45 & 22,22 \\
\hline 5 & $\mathrm{P}-4$ & $2,238.5$ & 50.32 & 10.23 & 39.45 & 0.00 & 0.00 & 11,73 \\
\hline 6 & $\mathrm{P}-5$ & 2,294 & 75.07 & 6.19 & 18.74 & 0.00 & 0.00 & 32,64 \\
\hline 8 & $\mathrm{P}-6$ & 2,325 & 58.73 & 0.47 & 40.80 & 0.00 & 0.00 & 21,40 \\
\hline 10 & $\mathrm{P}-7$ & 2,380 & 79.84 & 0.00 & 20.16 & 0.00 & 0.00 & 33,65 \\
\hline 12 & $\mathrm{P}-8$ & 2,160 & 56.11 & 0.00 & 43.89 & 0.00 & 0.00 & 13,01 \\
\hline \multicolumn{2}{|c|}{ Total } & $\mathbf{1 8 , 1 7 9}$ & - & - & - & - & - & 167.92 \\
\hline
\end{tabular}


Table 4. Extraction of gold on the jigging machine with a change in the stroke of piston at a frequency of $200 \mathrm{rpm}$

\begin{tabular}{|c|c|c|c|c|c|c|c|c|}
\hline \multirow[b]{2}{*}{$\begin{array}{c}\text { Piston } \\
\text { stroke, } \\
\text { mm }\end{array}$} & \multirow[b]{2}{*}{$\begin{array}{l}\text { No. of } \\
\text { sample }\end{array}$} & \multirow[b]{2}{*}{$\begin{array}{c}\text { Mass of } \\
\text { sample, } \\
\mathrm{g}\end{array}$} & \multicolumn{5}{|c|}{ Yield of $\mathrm{Au}, \%$} & \multirow[b]{2}{*}{$\begin{array}{c}\text { Total } \\
\mathrm{Au}, \mathrm{mg}\end{array}$} \\
\hline & & & $\begin{array}{c}\text { Top } \\
\text { chamber } \\
1\end{array}$ & $\begin{array}{c}\text { Top } \\
\text { chamber } \\
2\end{array}$ & $\begin{array}{l}\text { Underflow } \\
\text { chamber } 1\end{array}$ & $\begin{array}{l}\text { Underflow } \\
\text { chamber } 2\end{array}$ & Jig tailings & \\
\hline 1.5 & E-1 & 2,222 & 73.85 & 0.00 & 10.80 & 0.00 & 0.00 & 41,3 \\
\hline 3 & E-2 & $2,227.5$ & 64.27 & 0.00 & 35.73 & 0.00 & 0.00 & 38,9 \\
\hline 4 & E-3 & 2,228 & 75.59 & 0.00 & 24.41 & 0.00 & 0.00 & 51,2 \\
\hline 5 & E-4 & 2,223 & 60.71 & 0.00 & 39.29 & 0.00 & 0.00 & 50,9 \\
\hline 6 & E-5 & $2,226.5$ & 69.26 & 0.00 & 30.74 & 0.00 & 0.00 & 61,15 \\
\hline 8 & E-6 & $2,228.5$ & 51.51 & 0.00 & 48.59 & 0.00 & 0.00 & 40,85 \\
\hline 10 & E-7 & $2,149.5$ & 66.19 & 0.00 & 33.81 & 0.00 & 0.00 & 84,3 \\
\hline 12 & E-8 & $1,990.5$ & 70.27 & 0.00 & 29.73 & 0.00 & 0.00 & 50,45 \\
\hline \multicolumn{2}{|c|}{ Total } & $17,495.5$ & - & -- & -- & & & 419.05 \\
\hline
\end{tabular}

The parameters of the technological processes of the jigging machine with Alaska-35 washing device have been analyzed, the matrix of interacting factors (such as the shape of the mineral particles, the particle size, the particle density, the height of the jig bed, the oscillation frequency of the piston, the piston stroke), was made, studying which will make it possible to obtain graphically-analytical dependences of the calculation of their rational parameters that ensure effective extraction of the metal.

\section{References}

1. S.G. Kashuba, V.N. Ivanov. Gold and Technology. 3 (37). pp. 6 - 9. (2017).

2. V.S. Litvintsev, A.P. Van-Van-Ye, Aleksandrova, TN, Korneeva, SI. A separate article of the Mountain Information-Analytical Bulletin (scientific and technical journal). 3. 12 p. (2012).

3. Business Directory Far East. Gold of Far East and the Baikal region in 2016. Retrieved at: minvr.ru/upload/iblock/40f/Декларация-2017.pdf

4. R.S. Seryi, P/P. Sas, X Congress of Concentrators of the CIS countries. Collection of Materialov. 2. P. 421-424. (2015).

5. Z.G. Mirzekhanova, G.S. Mirzekhanov, V.S. Litvintsev, Retrospective Analysis of the Formation of Resource-Ecological Problems in the Development of Alluvial Gold Deposits / Pacific Geology. 2. P. 95-108. (2016).

6. Ackles, D. Gold is where you find it. Authorhouse. Includes an account of the effective use of innovative IHC jigs at Gold Dust Creek in Alaska. 116 p. (2006).

7. Ackels, D., Madonna J. Placer Mining in Alaska with IHC jigs. Alaskan Prospectors and Miners News, Fall Edition. 9 p. (1985). 